\title{
Revisión sobre literacidad como noción multidimensional para una Didáctica de las Lenguas inclusiva
}

\author{
Eva M. ${ }^{\mathrm{a}}$ IñESTA MenA \\ Universidad de Oviedo
}

Recibido: 8 julio 2016 / Aceptado: 20 octubre 2016

ISSN: $1697-7467$

\begin{abstract}
RESUMEN: El objetivo del estudio es analizar las nociones de literacidad, en español, y littératie, en francés, mediante una revisión crítica de publicaciones sobre el sentido de estos conceptos frente a alfabetización (alphabétisation), y en relación al inglés literacy. Se explica el origen de distintas líneas de estudio, y el desarrollo de investigaciones del área francófona de Canadá, donde literacidad es entendida como la capacidad de apropiarse de la cultura oral y escrita en toda su riqueza de formas y recursos para interactuar, comunicar, aprender y socializar. Se perfila una conceptualización multidimensional, desde una visión ecológica de la enseñanza y aprendizaje de lenguas, con la inclusión y el plurilingüismo entre sus referentes.
\end{abstract}

Palabras clave: Didáctica de las Lenguas, alfabetización, literacidad, inclusión, plurilingüismo.

\section{A review on Literacy as a multidimensional notion for an inclusive Didactics of Lan- guages}

\begin{abstract}
The aim of the work is to analyze the Spanish notion of literacidad and the French littératie, by a critical review of papers about the meaning of these concepts with regard to alfabetización ((alphabétisation), and the English literacy. The origin of different approaches and the development of research in the French area of Canada, where litter ratie is understood as the ability to acquire the oral and written culture, with all its diversity of forms and resources to interact, communicate, learn and socialize is also explained. A multidimensional concept is outlined from an ecological approach of languages teaching and learning, with inclusion and plurilingual competence among his points of reference.
\end{abstract}

Keywords: Didactics of languages, literacy, inclusion, plurilingual competence.

\section{INTRODUCCIÓN}

La alfabetización es un desafío global para las políticas educativas internacionales, pendientes de alcanzar la meta de alfabetización para todos (Richmond et al. 2008). Esta noción pasó de considerarse "una destreza simple y elemental" a ser reconocida como "un concepto complejo y dinámico, un contenido y un proceso de aprendizaje que dura toda la vida, y cuyos dominios y aplicaciones están en continua revisión y expansión" (UNESCO, 2000: 8). La renovación conlleva, entre otros factores, atender al "desarrollo de la expresión y la 
comunicación tanto oral como escrita, con una visón del lenguaje como totalidad" (UNESCO, 2000: 10). Sobre la expansión de este concepto, ya sea vehiculado por 'alfabetización' o 'literacidad', trata este estudio; una revisión bibliográfica que pretende explicar la relación que se establece entre ambos términos y la especialización que va adquiriendo 'literacidad' en el ámbito de la didáctica del área francófona canadiense. El objetivo último de la revisión es definir literacidad como un concepto operativo que puede orientar la enseñanza y aprendizaje de las destrezas comunicativas, independientemente del contexto (aulas de lengua materna, segundas lenguas o extranjeras, en educación reglada o formación no reglada).

La UNESCO emplea en sus publicaciones alfabetización, alphabétisation en francés, como equivalentes del inglés literacy, mientras que en otros contextos aparecen literacidad o littératie (OCDE y Statistique Canada, 1995). Literacidad no siempre coincide con el sentido de littératie; además, se percibe aun como anglicismo. Estas fluctuaciones terminológicas, interlingüísticas e intralingüísticas, se manifiestan en algunas situaciones como sinonimia contextual, mientras que en otras parece generarse una progresiva relación de inclusión en la que literacidad actuaría como hiperónimo. La pluralidad de significados vehiculados por estos términos se explicaría por las distintas necesidades formativas y educativas de cada época o sociedad, y por las respuestas que desde la acción del aula se van dando. Recientemente, Lafontaine y Pharand (2015: 2) $)^{1}$ comentan e ilustran la polisemia de littératie; sin embargo, la inestabilidad en la correspondencia de significados entre idiomas, aun ciñéndose al inglés, francés y español, dificulta la interpretación de textos de especialidad, lo cual motiva la revisión que se presenta, en la que se llega a una noción abierta, con un gran potencial teórico y práctico para la enseñanza y aprendizaje de lenguas. En el Canadá francófono se acota un concepto multidimensional que cubre tanto el desarrollo de las destrezas escritas como orales, en cuanto pilares de otros aprendizajes a lo largo de la vida, favoreciendo la construcción de la propia identidad y la integración social. Es una perspectiva coherente con los retos socioeducativos y valores democráticos que atañen a la Didáctica de las Lenguas y Culturas.

Se exploran aquí trabajos de distintos ámbitos -anglosajón y francófono mayormenteque muestran la coexistencia de 'alfabetización' y 'literacidad', revelando los orígenes del objeto de estudio, su evolución y distintos sentidos. Articulan el estudio investigaciones de Barton, Hamilton e Ivanič (2000); Barton y Hamilton (2010); Régine (2003); Cassany (2005); Cassany y Casatellà (2010); Fraenkel y Mbodj (2010); Rispail (2011); Dumais (2011); Hébert y Lafontaine (2010); Hébert y Lépine (2012); Lafontaine (2013); Moreau, Hébert, Lépine y Ruel (2013); Lafontaine y Dumais (2014), y Lafontaine y Pharand (2015).

La presentación responde a las distintas conceptualizaciones revisadas: se empieza recordando la noción manejada en las iniciativas de la UNESCO; a continuación se explica la génesis de las corrientes de estudio anglosajonas, cuya influencia llega al ámbito iberoamericano desde la literacidad crítica; se sintetiza después un estado de la cuestión del área francófona, destacando su vínculo con plurilingüismo e inclusión, y se concluye valorando el potencial de estas últimas aportaciones. Se ponen así de relieve diferencias de sentido que resultarán útiles para los docentes o didactas que se mueven entre lenguas, junto con pistas interesantes para guiar la acción en las aulas entre textos, hipertextos o textos multimodales.

\footnotetext{
${ }^{1}$ Didactas del ámbito francófono canadiense que desarrollan sus investigaciones en el marco del grupo ERLI Équipe de recherche en littératie et inclusion (Equipo de investigación en literacidad e inclusión).
} 


\section{La ALFABetización desde la Unesco}

La UNESCO emprendía a finales de los años 50 campañas para la formación de adultos, con vistas a la integración social, introduciendo en inglés el concepto de "funcional literacy" tomado de Gray (1956). Pierre (2003: 2) explica al respecto cómo el traductor de esta obra al francés había preferido emplear "instruction fonctionnelle" por evitar lo que entendía habría sido un calco, dando origen a la confusión de los conceptos de "alphabétisation" y "éducation fondamentale" ('educación básica'); y cómo en la traducción francesa de la obra de Teale $(1982 ; 1983)$ se optó por 'alphabétisation' -para 'literacy'-, con nota al pie para indicar que Pierre había defendido "littératie" (escrito entonces como litéracie, y littéracie). Un par de años después aparecía la considerada como la primera publicación en la que se emplea literacidad en francés, de Giasson et al. (1985) y con Pierre entre sus autores.

La Declaración Mundial sobre Educación para Todos (Jomtien, Tailandia, 1990) aportó una nueva visión de la educación básica, referida a "una educación capaz de satisfacer las necesidades básicas de aprendizaje de todos -niños, jóvenes y adultos- a lo largo de toda la vida, dentro y fuera de la escuela." (UNESCO, 2000: 2). Pierre (2003) señalaba que fue invitada a exponer la nueva conceptualización y el uso de littératie en la conferencia inaugural del Congreso mundial sobre ciudadanía de la UNESCO, celebrado en París en 1993 (Pierre, 1994). El interés hacia su propuesta por parte del Bureau de l'éducation fondamentale se vio reflejado en la colaboración de la UNESCO con la primera investigación internacional de la OCDE y Statistique Canada (1995): Littératie, économie et société. No obstante, la polémica surgida por la inclusión de este término llevaría a Statistiques Canada a retomar alphabétisation en publicaciones posteriores. El reto de una educación para todos orientó el Foro Mundial de la Educación (Dakkar, 2000), donde se desarrolló la sesión estratégica especial: "Alfabetización para Todos: Una visión renovada para un plan decenal de acción" (2000), que daría lugar a la proclamación de la Década de la alfabetización (2003-2012) y a la designación del 8 de septiembre como su Día Internacional. Estas iniciativas de la UNESCO son tituladas en inglés como Literacy decade, International Literacy Day; en francés, Décennie de l'alphabétisation, Journée internationale de l'alphabétisation. Por tanto, este organismo desestimó el empleo de littératie, aun reconociendo la necesaria expansión del concepto expresado por alphabétisation. No obstante, en las publicaciones especializadas francófonas sí fue incorporado, alegando que alphabétisation no daría cuenta de situaciones de apropiación de la escritura que pudieran desarrollarse de manera natural, incluso antes de su enseñanza formal en situación escolar (Pierre, 2003).

El siguiente texto publicado con motivo del Día Internacional de la Alfabetización, cuyo tema de 2014 era "alfabetización para el desarrollo sostenible", muestra la perspectiva de la UNESCO:

La alfabetización es la base del aprendizaje a lo largo de toda la vida y desempeña una función esencial en la creación de sociedades sostenibles, prósperas y pacíficas. Las competencias de lectura, escritura y aritmética que se adquieren a lo largo de la vida, desde las nociones elementales hasta el nivel más avanzado, forman parte de un conjunto más amplio de capacidades necesarias para desarrollar el pensamiento crítico, el sentido de la responsabilidad, la participación cívica, el consumo y los estilos de vida sostenibles, las conductas ecológicas, la protec- 
ción de la biodiversidad y la reducción de la pobreza y del riesgo de desastres. (UNESCO, 2014)

Quizá la imagen de la "base", como metáfora espacial, condiciona la representación que se tiene del concepto de alfabetización, cercana a la de "fundamento" ("éducation fondamentale'). Parece poner trabas a la comprensión del sentido más amplio que el concepto va adquiriendo para cubrir la educación a lo largo de la vida e incorporando competencias a medida que las necesidades evolucionan. Las acciones emprendidas por la UNESCO responden a dicha expansión conceptual, sin embargo alfabetización no se interpreta claramente en este sentido. No ocurre lo mismo con el término 'clave', por ejemplo en 'competencias clave', pues éste no sitúa en un punto extremo, sino nuclear, con lo cual es más fácil percibir la evolución en la complejidad. Así, voces críticas provenientes del ámbito francófono canadiense, partidarias del uso de literacidad, recuerdan que el ejercicio de una ciudadanía activa y crítica requiere la movilización de todas las competencias clave, comenzando por el desarrollo de la comunicación oral (Consejo de Educación de la U.E., 2006).

Si el término 'alfabetización' vincula con la formación inicial, al igual que 'alfabetización funcional', tiene cabida la propuesta de littératie/literacidad, para vehicular los sentidos expandidos de alfabetización, aunque no sea la opción terminológica elegida por la UNESCO. En cualquier caso, también los nuevos conceptos de alfabetización mediática e informacional, alfabetización digital, fluctúan en francés entre l'éducation aux médias et à l'information; alphabétisation numérique y littératie numérique et de l'éducation, littératie médiatique.

\section{De los estudios de literacidad a LOS NUEVOS ESTUdios}

Fraenkel y Mbodj (2010: 10) atribuyen la diversidad de sentidos del término en inglés y de las orientaciones de los estudios correspondientes a la propia complejidad de 'literacy', cuyas raíces semánticas aluden tanto a aspectos formales de aprendizaje como a la relación con una cultura letrada, lo cual reenvía a su vez a jerarquías sociales. Algo similar puede decirse de 'letrado' en español frente a 'iletrado'. Esta oposición explicaría la separación surgida en la corriente de los Estudios de literacidad entre dos modelos: uno representado por la obra de Goody (Goody y Watt, 1963), el llamado modelo autónomo, que consideraba que de un conjunto de competencias solo cabía esperar idénticos resultados; y otro llamado ideológico, representado por Street $(1984,1993,1995,2000)$, que superaba la visión reducida de las competencias para contemplar prácticas situadas en contextos precisos de usos sociales, invalidando las teorías sobre posibles efectos de las mismas, ya fueran estos cognitivos o sociales. Esta perspectiva es la seguida por los llamados Nuevos Estudios de Literacidad.

Los orígenes del modelo ideológico se remontan a la obra de corte autobiográfico del antropólogo inglés Hoggart (1957) The Uses of Literacy, considerada la primera investigación etnográfica sobre prácticas de literacidad. En ella se describía el estilo de vida de las clases populares de la Inglaterra industrial del noreste, donde la lectura no respondería al ideal escolar de la tradición letrada sino a un uso inmediato y placentero, específico del hogar. Esta metodología empírica fue adoptada por las investigaciones que en torno a la escritura se desarrollaron en los años 80 desde la antropología, la sociolingüística, o la etnografía de la comunicación. Los trabajos de orientación etnográfica ejercieron una influencia decisiva 
en la corriente de estudio, dotándola de nuevos conceptos e instrumentos, como a continuación se describe.

Entre los pioneros se sitúan Scribner y Cole (1981; 2010), quienes focalizaron el concepto de práctica a partir de una investigación desarrollada entre la población Vaï de Liberia, que les permitió comprobar la repercusión de tres aprendizajes distintos de la escritura, cada uno asociado a una lengua y a un contexto: la lengua vaï, cuya escritura se aprendía en un marco informal; inglés, como lengua de la administración enseñada en la escuela; árabe, de uso religioso y por lo tanto adquirida en la escuela coránica. Se demostraba que los efectos cognitivos atribuidos hasta entonces al mero aprendizaje de la lectoescritura, se debían más bien a que dicho aprendizaje tenía lugar en un contexto escolar. El concepto de práctica adquiere entonces relevancia, aunando una tecnología, su conocimiento y un saber hacer. Sucesivos trabajos en torno a la escritura contextualizada se basan en esta investigación.

Relevante fue también Heath (1982) pues aportó la noción de evento (literacy event). Durante diez años se ocupó de la escritura en el seno de dos comunidades obreras de Carolina del Norte (una de raza blanca y otra negra) frente a una población urbana de clase media. Pretendía revelar las dificultades de comunicación experimentadas en la escuela por niños procedentes de entornos populares, para lo cual analizó las relaciones que mantenían con la escritura en edad preescolar, en el núcleo familiar o comunitario, sirviéndose de la noción de literacy event ilustrada mediante los momentos de lectura de cuentos de antes de dormir. Evento pasaría a ser de uso generalizado en los Nuevos Estudios de Literacidad de orientación etnográfica (Fraenkel, Mbodj, 2010).

Posteriormente, Street $(1984,1995)$ confirmaría las tesis de Scribner y Cole sobre pluralidad de formas sociales de usos del escrito, pero destacando la transferencia que puede darse entre las mismas, de manera que lo aprendido en una escuela coránica para fines religiosos sería transferible a usos comerciales, por ejemplo. Una obra colectiva dirigida por el mismo autor, Street (1993), Cross-cultural approaches to literacy, impulsaría la orientación antropológica, contribuyendo a la difusión del término de New Literacy Studies (NLS) (tomado de Gee, 1990). Basándose en una síntesis de trabajos, Street proponía un marco metodológico articulado en torno a las nociones de eventos y prácticas de literacidad. Así pues, esta nueva corriente seguía el método etnográfico defendiendo un enfoque contextualizado para el estudio de los usos de la escritura, si bien, llama la atención la falta de referencias a la comunicación oral, siendo esta la destreza privilegiada en etnografía.

Las propuestas de Street serían aplicadas y desarrolladas por Barton y Hamilton (1998; 2010), desde la Universidad de Lancaster. La influencia de estos trabajos llegaría a la UNESCO, pues se proyectaban por aquellos años las iniciativas sobre alfabetización universal. Las similitudes entre esta orientación y las propuestas pedagógicas de alfabetización de Freire contribuirían a reforzar su alcance (Fraenkel, Mbodj, 2010: 14). Barton y su equipo definen una teoría social de la literacidad, según la cual, las prácticas sociales de la escritura se ven determinadas culturalmente (Barton, 1994; Barton, Hamilton e Ivanič; 2000; Barton y M. Hamilton, 2010). Por prácticas no se refieren simplemente a la resolución de tareas y actividades como comportamientos observables, o tareas comunes, (interpretación de la OCDE presente también en otras orientaciones de la literacidad) sino que las prácticas adquieren un sentido más abstracto, englobando los usos de la escritura en el seno de una cultura, implicando valores, actitudes, sentimientos, relaciones sociales, además de una conciencia sobre la misma (Barton y Hamilton 2010: 46). La parte interna del proceso se manifiesta en los 
discursos (Barton et al., 2000: 7). Tales prácticas suponen ideologías, identidades, y vienen determinadas por las normas que regulan el uso de los textos, o el acceso a los mismos. En cuanto al concepto de evento, se refiere a aquellas actividades observables y desarrolladas en torno a un texto, considerando igualmente el contexto social, lo cual coincide con las reflexiones de Bajtín sobre los géneros discursivos, o con otras propuestas sociolingüísticas (Fraenkel y Mbodj, 2010; Cassany y Castellà, 2010).

Los autores de los Nuevos Estudios consideran cruciales los textos que forman parte de la vida diaria de las personas, porque permiten conectar con sus acciones y ayudan a comprender qué suponen para cada uno. Esta teoría fue explicada en Barton et al. (2000: 9), y revisada en Barton y Hamilton (2010: 45-46) mediante seis propuestas, que se presentan aquí adaptadas al español. En ellas, literacidad se refiere a prácticas escritas:

- La literacidad se comprende mejor si es abordada como un conjunto de prácticas sociales, observables en eventos en los que los textos desempeñan un papel central.

- Cada ámbito de la vida engloba una literacidad (que implicará distintos tipos o medios de comunicación).

- Las instituciones sociales (familias, religión, educación...) moldean las prácticas, por lo que unas son más visibles, más dominantes e influyentes que otras.

- Las prácticas de escritura van insertas en objetivos sociales y culturales mayores; de ahí que haya que situar las actividades de lectura y escritura respecto a dichos fines y propósitos. Por ejemplo, si se prepara un pastel, lo importante es el pastel, siendo la lectura de la receta algo secundario. Esa actividad, a su vez, implica prácticas sociales relativas a las tareas del hogar, la vida en familia, etc.

- La literacidad está históricamente determinada, como todo fenómeno cultural.

- Las prácticas de literacidad se renuevan, adquiriéndose otras mediante procesos de aprendizaje y de creación de sentidos informales.

En esta concepción de la literacidad (literacy), aunque referida al escrito, sí está presente la idea de renovación o evolución en función de prácticas sociales que les dan sentido, aspecto que parece escapar de la noción de alfabetización de la UNESCO.

\section{Literacidad CRÍTICA}

Una perspectiva sociocultural similar en torno a la escritura y la lectura es adoptada por la línea de investigación de literacidad crítica de Cassany. Este autor analiza la riqueza de formas que adopta: la "multiliteracidad", prácticas de lectura que implican rápidos y sucesivos cambios de género, idioma, propósito, soporte etc.; "biliteracidad", cuando se manejan dos idiomas; o "literacidad electrónica", en relación a los géneros que surgen con la expansión de internet. Tal flujo de tareas en torno a los textos lleva a justificar la "criticidad" como necesario objeto de estudio de la Didáctica de las Lenguas, en cuanto responsable de proporcionar herramientas eficaces que faciliten a los docentes el manejo de dichas situaciones (Cassany, 2005). Cassany y Castellà (2010: 358) sintetizan las distintas corrientes que nutren la literacidad crítica: junto a la Pedagogía crítica (Freire, Giroux) y los Nuevos Estudios de Literacidad (Gee, Barton...), sitúan las ciencias del lenguaje (van 
Dijk...), los estudios lingüísticos y literarios (Halliday, Bajtín), el Postestructuralismo (Derrida, Foucault), la Teoría Crítica de la Escuela de Frankfurt (Adorno, Habermas...). Cassany y Castellà (2010) focalizan por tanto los textos escritos desde una fructífera perspectiva que conecta con la realidad del uso:

El concepto literacidad (literacy en inglés) incluye un amplio abanico de conocimientos, prácticas sociales, valores y actitudes relacionados con el uso social de los textos escritos en cada comunidad. En concreto, la literacidad incluye el dominio y el uso del código alfabético, la construcción receptiva y productiva de textos, el conocimiento y el uso de las funciones y los propósitos de los diferentes géneros discursivos de cada ámbito social, los roles que adoptan el lector y el autor, los valores sociales asociados con estos roles (identidad, estatus, posición social), el conocimiento que se construye en estos textos y que circula en la comunidad, la representación del mundo que transmiten, etc. (Cassany y Castellà, 2010: 354).

\section{Literacidad EN El Ámbito FRANCófono}

En el área francófona de Canadá se destacaba tradicionalmente littératie en relación a lectura y escritura, pero se amplió esta visión para integrar la oralidad, comprendiendo la relación entre destrezas. Dumais (2011) analiza la heterogeneidad de definiciones en el ámbito educativo de este contexto, señalando la falta de consenso entre los programas de estudio de cada provincia. No obstante, indica cómo las nuevas investigaciones van llegando a puntos de convergencia que renuevan el concepto. Se muestran a continuación tres de las definiciones destacadas por este autor, comenzando por la del Departamento de Educación de Ontario, una de las más difundidas:

[...] la capacité d'utiliser des formes riches et variées d'expressions orale, écrite ou visuelle pour lire, écrire, écouter, parler, visualiser, représenter et réfléchir de façon critique aux idées les plus diverses. Elle permet de partager de l'information, d'interagir avec autrui et de saisir le sens des choses. La littératie est un processus complexe par lequel une personne acquiert de nouvelles connaissances et une meilleure compréhension du monde qui l'entoure en puisant dans sa culture, son vécu et son acquis. Indispensable à la croissance personnelle et à une participation active à la vie d'une société démocratique, elle permet de tisser des liens entre particuliers et entre collectivités. (Ministère de l’Éducation de l’Ontario, MÉO, 2011)

[...] des habiletés de haut niveau telle la capacité d'utiliser le langage et les images, de formes riches et variées, pour lire, écrire, écouter, parler, voir, représenter et penser de façon critique. (Hébert y Lafontaine, 2010: 4).

[...] les capacités d'utiliser le langage et les images de formes riches et variées pour voir, écouter, parler, lire, écrire, comprendre, communiquer, penser de façon 
critique afin d'atteindre un but et de développer ses connaissances en classe, à l'école, à la maison ou dans la communauté. (Moreau, Leclerc y Landry, 2010: 43).

¿Qué añade literacidad a alfabetización que justifique el empleo del término? Los miembros del grupo ERLI - Équipe de recherche en littératie et inclusion, se planteaban esta pregunta que tanta polémica había suscitado décadas atrás. En Hébert y Lépine (2012) y Moreau et al. (2013) se publican los resultados de una extensa investigación sobre las dimensiones que pudieran justificar su uso en francés, desentrañando los valores añadidos al concepto básico de saber leer y escribir. Se trata de una revisión de las definiciones (excluyendo derivados) manejadas durante un periodo de 25 años en documentos del espacio francófono del norte (publicaciones científicas, obras de referencia, currículos escolares, desde 1985). Hébert y Lépine (2012) se suman a la constatación de Grossmann (1999: 142) de que la noción desestabiliza las fronteras generalmente reconocidas entre los distintos componentes de la enseñanza de la lengua materna, a saber, la lectura, la escritura y lo oral. Citan a Lebrun (2007) para señalar que se trata de una noción multidimensional cuyos contornos son aún difusos. No obstante, su estudio les permite aportar hasta diez valores añadidos al saber leer y escribir, y coinciden con Dumais (2011) para lamentar el escaso impacto de esta noción en los currículos y programas escolares de Canadá, a pesar de responder a los principales retos destacados para la escolarización desde los años 90. En aquella época se desencadenaban los procesos de globalización, y sucedía un intercambio de conceptos entre el ámbito escolar y el económico, impulsado por organismos internacionales. Como se indicaba más arriba, fue en 1995 cuando el término comenzó a difundirse en este área, en el marco de las iniciativas de la División de Educación Básica de la UNESCO, a través de la encuesta Littératie, économie et société (OCDE y Statistique Canada), un estudio que precede la gestación de los programas de evaluación internacional PISA (Hébert y Lépine, 2012: 89). Seleccionan en este trabajo tres definiciones representativas del ámbito francófono: la de Giasson et al. (1985), como pionera; la de Jaffré (2004) por ser la más citada; y la de Rispail (2011), cronológicamente, la última de la muestra.

Los diez valores añadidos, según estas autoras ${ }^{2}$ se presentan a continuación (adaptados al español, y respetando la cursiva del original). Hébert y Lépine (2012: 88):

1. Objetivos plurales, perspectiva plural, interdisciplinar, sobre objetivos y retos personales, profesionales, socioculturales relacionados con la apropiación del escrito.

2. Conjunto de actitudes, conocimientos, habilidades y competencias relacionados con la apropiación de la cultura escrita (y a desarrollar por el aprendiente), la interrelación compleja de estos aspectos afectivos, cognitivos y socioculturales en la enseñanzaaprendizaje.

3. Variedad de textos (académicos, sociales), géneros, soportes, discursos, prácticas y tecnologías de la información y de la comunicación (TIC) a considerar.

4. Aspecto dinámico, variable, situado, leer-escribir son un constructo social que varía en el tiempo y en el espacio.

${ }^{2}$ La publicación de Hébert y Lépine (2012) incluye conceptos clave, frecuencia de aparición y el listado de los trabajos analizados. 
5. Relaciones individuo-sociedad, leer-escribir permite desarrollar la identidad individual, favorecer la integración o la exclusión social.

6. Tareas reales auténticas, extraescolares y escolares, medir las habilidades en situaciones variadas.

7. Concepto positivo y continuo, «nunca se parte de cero », y además evolución posible a lo largo de la vida.

8. Interdependencia-interferencia escrito-oral, relaciones entre la escritura y lo oral, de qué manera uno puede servir de palanca o no para el aprendizaje del otro y viceversa.

9. Influencia del entorno sobre la escuela y en los aprendizajes, pero asimismo influencia de la escritura sobre las estructuras sociales.

10. Intención o finalidad emancipadora, progresista, humanista, desarrollo integral de la persona.

\subsection{Literacidad para la inclusión}

En el marco de la misma investigación, Moreau et al. (2013) entienden la literacidad como noción abierta, dinámica y contextualizada, con tres dimensiones: lingüística, cognitiva y social. El último aspecto, relativo al desarrollo integral de la persona, sería para los autores el más relevante, y el que mejor marcaría la diferencia respecto a la noción básica de leerescribir. Esta literacidad abriría la puerta a distintos objetivos de investigación, a menudo interdisciplinares, que implican la esfera personal, la esfera profesional y la sociocultural, relacionadas con el aprendizaje de la lengua oral y escrita, situada en contextos sociales precisos, en una dimensión ecológica:

Le terme littératie s'inscrit dans une approche paradigmatique d'unification de connaissances reconnues dans les écrits scientifiques. Dans ce sens, la littératie renvoie à l'idée générale de l'étude de la langue orale et écrite située dans des contextes sociaux précis, dans une dimension écologique. (Moreau et al., 2013:17).

Asimismo, resaltan que esta visión se hace necesaria por su referencia positiva a un proceso continuo de desarrollo de competencias orales, lectoras, escritas, frente a planteamientos más restrictivos del concepto de alfabetización. Precisamente, este factor es clave para investigaciones orientadas hacia la participación de personas vulnerables, o marginadas por sus competencias reducidas. Los autores alertan sobre la necesidad de investigar los medios que permitirían a distintos organismos y servicios llegar a las personas con competencias limitadas en literacidad, respondiendo a sus necesidades y favoreciendo una comunicación recíproca que contribuyera a crear entornos inclusivos:

Somme toute, les chercheurs francophones soulignent sur un plan théorique et heuristique les avantages du concept de littératie dans son sens large tant sur le plan anthropologique que sociologique, entre autres. Néanmoins, les recherches futures en matière de littératie devraient s'intéresser aux moyens qui permettraient aux services ou aux organisations de mieux atteindre les populations ayant des compétences réduite en littératie afin de mieux répondre à leurs besoins et de 
favoriser une communication réciproque et ce faisant de contribuer à rendre leur milieu inclusif (CIRLI, 2013). (Moreau et al., 2013: 17).

El compromiso con la inclusión social se materializa en iniciativas como las emprendidas por la Chaire interdisciplinaire de recherche en littératie et inclusion (Cátedra interdisciplinar de investigación en literacidad e inclusión) (CIRLI, 2013) o por el Équipe de recherche en littératie et inclusion (Equipo de investigación en literacidad e inclusión) (ÉRLI, 2013), liderados por investigadores ya citados, como Ruel, Lafontaine, Moreau, Hébert, o Dumais.

Lafontaine (2013) señala, en sintonía con las recomendaciones de la UNESCO pero destacando la oralidad, que el desarrollo de las competencias en literacidad es un reto social, una condición fundamental para el acceso al saber. Se trata de una competencia general unida a la apropiación de la cultura oral y escrita necesaria para que cada persona pueda relacionarse con los demás y con el mundo: interactuar, comunicar, aprender y socializar (OCDE: 2003). Para todo ello se hace necesario aunar literacidad e inclusión (Richmond et al., 2008; Hébert y Lafontaine, 2010).

Hay que señalar que en la base de algunas propuestas didácticas del grupo pluridisciplinar de Quebec, ERLI, se hallan las concepciones de los géneros y la planificación mediante secuencias didácticas de Dolz y Schneuwly (1998), o Dolz, Novarraz y Schneuwly (2001). Se expande una corriente nutrida por una confluencia de aportaciones como las de Tompkins (2006) sobre estrategias; las herramientas y prácticas para la inclusión de Hébert y Lafontaine (2010); los centros de literacidad de Diller (2011); o los talleres para lo oral de Lafontaine y Dumais (2014). En esta línea, el monográfico de Lafontaine y Pharand (2015) aporta interesantes investigaciones e innovaciones en torno a la literacidad en distintos contextos y niveles educativos, desde la educación infantil a la universidad, mostrando las múltiples competencias que implica: literacidad en las distintas disciplinas, mediática, multimodal, e incluso literacidad emocional.

\subsection{Literacidad y plurilingüismo}

Desde la didáctica de las lenguas extranjeras, siguiendo las directrices del Marco común europeo de referencia para las lenguas: aprendizaje, enseñanza, evaluación (MCER) del Consejo de Europa (2002), resulta sencillo vincular estos fines con el tratamiento en el aula de una competencia en comunicación plurilingüe e intercultural. Se trata de plantear tareas en torno a textos (o hipertextos, textos multimodales) que: favorezcan la movilización de distintos saberes y destrezas, orales y escritas; estimulen las distintas lenguas del repertorio personal de los aprendices, en función de las necesidades del contexto; supongan el acceso a distintos soportes, y medios digitales (Raspail, 2011). Dado que le corresponde a la Didáctica de las Lenguas orientar las prácticas docentes en sintonía con los contextos sociales, es importante cuestionar los conceptos, abordándolos desde nuevas perspectivas que faciliten una visión más amplia del terreno; en este sentido, esta conceptualización parece una herramienta facilitadora, pues ayuda a comprender mejor la importancia de manejar los distintos tipos de textos en su contexto de uso, las prácticas sociales. La conexión con las prácticas y la referencia en positivo al aprendizaje hacen que la consideración de la diversidad lingüística, cultural y la inclusión sean planteamientos obvios. 


\section{Conclusión}

Hébert y Lépine (2012: 95-96) sugerían la necesidad de vincular las investigaciones sobre literacidad con los elementos del triángulo didáctico para analizar cómo esta noción, configurada a lo largo de los últimos 30 años, podría influir en otras consideraciones de los objetos de enseñanza y aprendizaje. Ahora bien, cabría preguntarse si realmente estaría claramente representada en dicho triángulo la perspectiva humanista, emancipadora, crítica e integral que facilita la literacidad, y que sería una de sus mayores aportaciones, según se ha mostrado en esta revisión (desde los Nuevos Estudios, la literacidad crítica de Cassany, o desde la interpretación ecológica y multidimensional del ámbito francófono). Pueden recordarse igualmente las objeciones que hiciera Aguilar (2012) a esta representación, y a cómo estaría limitada mientras no se integren de manera explícita los nuevos contextos sociales.

La concepción multidimensional para el estudio de la lengua oral y escrita en contextos sociales precisos, desde la dimensión ecológica señalada por Hébert y Lépine (2012) y Moreau et al. (2013) proporciona un óptimo punto de mira a los docentes, facilitando un acercamiento entre los fines últimos de la educación y las tareas del aula. Dicha característica, si bien dificulta una definición mediante rasgos cerrados, sería sumamente productiva para orientar una praxis que responda a la diversidad, a las necesidades concretas de cada aprendiz, y estimule la tarea docente. Responde en este sentido a lo que Puren llama una de las pocas leyes "científicas" de la Didáctica de las Lenguas y Culturas, defendiendo un cierto grado de abstracción en la definición de conceptos, a saber, que cuanto más concretos sean, más dependientes o limitados a un contexto resultarán: “Tanto más concreto es un concepto, cuanto más restringido es su uso al contexto preciso en el que se elaboró” (Puren, 2004: 33).

Así pues, el uso del término literacidad (como littératie) responde a las actuales necesidades socioeducativas, en situaciones concretas, incluyendo la orientación de aprendizaje a lo largo de la vida, la inclusión y el plurilingüismo, ligados a la diversidad. Supone una idea positiva de suma de saberes, que acercan principios como los de Cummins (2011), relativos a la importancia de valorar y apoyar en la escuela el dominio de la lengua materna para la inclusión académica de alumnos con lenguas diversas, como referente para la reflexión (asimismo en las clases de lengua extranjera, recordamos). Esta perspectiva sociocultural debe dar vida a un enfoque además de comunicativo, orientado a la acción, como señala el MCER, aunque, sorprendentemente, no aparezca en este documento referencia alguna a alfabetización ni a literacidad. Esta ausencia sorprende, dado que el dominio de la lengua, al menos en teoría, se mide en positivo: el número de tareas que pueden llevarse a cabo, activando los distintos recursos, estrategias de todo tipo, en determinados ámbitos, manejando tipos de textos (orales o escritos), que activan las distintas competencias, generales o individuales y las propiamente lingüísticas (lingüísticas, sociolingüísticas y pragmáticas).

El concepto de literacidad, desde la perspectiva francófona que integra la oralidad, resultaría útil para la Didáctica de las Lenguas como enlace eficaz entre fines educativos y prácticas de aula; facilita un planteamiento de las mismas vinculadas a las prácticas sociales, en torno a los textos correspondientes, y manteniendo el necesario compromiso con la atención a la diversidad y la educación para todos a lo largo de la vida. 


\section{REFERENCIAS BIBLIOGRÁFICAS}

Aguilar, C. (2012). "Presentación: La didáctica de la lengua y la literatura y la teoría crítica", en Lenguaje y Textos, Revista de la SEDLL, 36: 5-14.

Barton, D. (1994). Literacy: An introduction to the Ecology of Written Language, Oxford: Blackwell.

Barton, D. y Hamilton, M. (1998). Local literacies. Reading and writing in one community. Londres: Routledge.

Barton, D. y Hamilton, M. (2000). "Literacy practices", in D. Barton, M. Hamilton e Ivanič, R. (2000). Situated Literacies: Reading and Writing in Context. Londres: Routledge, 7-15.

Barton, D. y Hamilton, M. (2010). "La littératie: une pratique sociale", en Langage et société, 2010/3 n $133: 45-62$.

Barton, D., Hamilton, M. e Ivanič, R. (2000). Situated Literacies: Reading and Writing in Context. Londres: Routledge.

Cassany, D. (2005). Investigaciones y propuestas sobre literacidad actual: multiliteracidad, internet y criticidad. Cátedra UNESCO para la Lectura y la Escritura. Universidad de Concepción, Chile.

Cassany, D. y Castellà, J.M. (2010). "Aproximación a la literacidad crítica", en PERSPECTIVA, Florianópolis, v.28, n. 2, 353-374. Disponible en http://repositori.upf.edu/handle/10230/21187

Consejo de Educación de la Unión Europea (2006). Recommendation of the European Parliament and the Council of 18 december 2006 on key competencies for lifelong learning. Bruselas: U.E.

Consejo de Europa (2002). Marco común europeo de referencia para las lenguas: aprendizaje, enseñanza, evaluación. Madrid : Ministerio de Educación /Instituto Cervantes/Anaya.

Cummins, J. (2011). De l'importance des données de la recherche empirique pour les politiques éducatives en faveur des apprenants en difficulté. Division des politiques Linguistiques, Estrasburgo, Consejo de Europa. Disponible en www.coe.int/lang/fr

Diller, D. (2011). Les centres de littératie pour les élèves de 8 à 12 ans. Une approche basée sur l'autonomie pour consolider les apprentissages en lecture, en écriture et en communication orale. (Adaptation de J. Proulx). Montréal: Chenelière éducation.

Dolz, J. y Schneuwly (1998). Pour un enseignement de l'oral : initiation aux genres formels à l'école, París, ESF, 163-169.

Dolz, J., Novarraz, M. y Schneuwly, B. (2001). S'exprimer en français : séquences didactiques pour l'oral et pour l'écrit. Bruselas : De Boeck.

Dumais, Ch. (2011). La littératie au Québec : pistes de solution à l'école préscolaire et primaire. Forumlecture.ch. 2011/2. Plate-forme internet sur la littératie.

Fraenkel, B. y Mbodj, A. (2010). "Les New Literacy studies, jalons historiques et perspectives actuelles", en Langage et société, $3 \mathrm{n}^{\mathrm{o}} 133: 7-24$.

Gee, J. (1990). Social Linguistics and Literacies. Ideology in Discourses, London: Falmer Press.

Goody, J. y Watt, I.P. (1963). "The Consequences of Literacy", en Comparative Studies in society and History, 5: 304-345.

Gray, W.S. (1956/1967). The Teaching of reading and writing: An international survey. Paris, UNESCO.

Grossman, F. (1999). "Littératie, compréhension et interprétation des textes", en Repères, 19: 139-166.

Heath, S. B. (1982). "What no bedtime story means: narrative skills at home and school", en Language in Society, 11: 49-76. 
Hébert, M. y Lafontaine, L. (éd). Littératie et inclusion: Outils et pratiques pédagogiques Québec : Presses de l'Université du Québec.

Hébert, M. y Lépine, M. (2012). "Analyse et synthèse des principales définitions de la notion de littératie en francophonie", en Lettrure n² : 88-98.

Hoggart, R. (1957). The Uses of Literacy, aspects of working-class life, with special references to publications and entertainments. (Trad. Esp. 2013: La cultura obrera en la sociedad de masas, Madrid: Siglo XXI)

Jaffré, J. P. (2004). "La litéracie : Histoire d'un mot, effets d'un concept ", en C. Barré-de Miniac, C. Brissaud y M. Rispail (Eds.), La littéracie: conceptions théoriques et pratiques d'enseignement de la lecture-écriture. París : L'Harmattan, 21-41.

Lafontaine, L. (2013). "Travailler la littératie volet oral au préscolaire et au $1^{\text {er }}$ cycle du primaire : ça nous parle! ", en AQEP, Vivre le primaire, vol. 26, nº 1 .

Lafontaine, L. y Dumais, Ch. (2014). Enseigner l'oral c'est possible! 18 ateliers formatifs clés en main, Montréal, Chenelière Éducation.

Lafontaine, L. y Pharand, J. (2015). Littératie : vers une maîtrise des compétences dans divers environnements. Collection Éducation-recherche : 37. Gatineau, Québec: Presses de 1'Université du Québec.

Lebrun, M. (2007). "Exploiter diverses formes de littératie dans la classe de français", en Le langage et l'homme, 42 (2) : 77-99.

Ministère de l'Éducation de l'Ontario, MÉO (2011; 2015). Qu'est-ce que la littératie? http:// www.atelier.on.ca/edu/core.cfm?p=literacyAbout.cfm\&navID-=literacyAbout\&L=2-

Moreau, A. C., Leclerc, M. y Landry, L. (2010). "Les ateliers de lecture et d'écriture au préscolaire : Expériences d'enseignement-apprentissage”, en M. Hébert y L. Lafontaine (éd), Littératie et inclusion : Outils et pratiques pédagogiques. Québec : Presses de l'Université du Québec, 37-57.

Moreau, A., Hébert, M., Lépine, M. y Ruel, J. (2013). “ Le concept de littératie en francophonie : que disent les définitions?", en Revue CNRIS : Magazine scientifique et professionnel, Vo. 4, 2 : 14-18.

OCDE (2003). Reading for change: Performance and engagement across countries. Paris: OCDE.

OCDE et Statistique Canada (1995). Littératie, économie et société : résultats de la première Enquête internationale sur l'alphabétisation des adultes, París y Ottawa : OCDE y Statistique Canada.

Puren, Ch. (2004). "Del enfoque por tareas a la perspectiva co-accional", en Porta Linguarum 1: $31-36$.

Régine, P. (2003). "Entre alphabétisation et littératie : les enjeux didactiques”, en Revue française de linguistique appliquée 1 /2003, Vol. VIII : 121-137.

Richmond, M.; Robinson, C. y Sachs-Israel, M. (eds.) (2008). The Global Literacy Challenge. París: UNESCO.

Rispail, M. (2011). Littéracie: une notion entre didactique et sociolinguistique -enjeux sociaux et scientifiques. Forum Lecture. Disponible en: www.leseforum.ch/myUploadData/ files/2011_1_Rispail.pdf

Street, B. (1984). Literacy in Theory and Practice. Cambridge: Cambridge University Press.

Street, B. (1993). Cross-cultural approaches to literacy. Cambridge: C. U. Press.

Street, B. (1995). Literacy events and literacy practices. Theory and practice in the New Literacy studies. En M. Martin-Jones y K. Jones (eds.), Multilingual Literacies. Amsterdam: Johns Benjamins, 17-29. 
Teale, W. (1982). "Toward a Theory of How Children Learn to Read and Write Naturally", en Language Arts, Vol. 59, 6: 555-569.

Teale, W. (1983). "Vers une théorie de l'apprentissage naturel de la lecture et de l'écriture", en Les Actes de lecture, vol. 4, 21-32.

Tompkins, G. (2006). 50 stratégies en littératie, étape par étape. Montréal : Chenelière Éducation. UNESCO (2000). Alfabetización para todos: Década de la Alfabetización de NNUU. Documento Base para Consulta, junio 2000. Disponible en OEI: Organización de Estados Iberoamericanos http://www.oei.es/alfabetizacion/decadalfabetizacion.pdf

UNESCO (2014). Agenda: Día Internacional de la alfabetización. Disponible en http://www. unesco.org/new/es/unesco/events/prizes-and-celebrations/celebrations/international-days/ literacy-day-2014/ 